\title{
DIGITALLY-PROCESSED CUSTOM PLATE VERSUS CONVENTIONAL PLATE FIXATION IN GENIOPLASTY
}

\author{
Khaled Amr*, Abd El-Monim Gh.* and Hussein Hatem **
}

\begin{abstract}
Purpose: The fundamental position of the chin contributes to the aesthetic perception of the face and the subsequent esthetic disharmony when deficient or retruded. In this study, we aimed to verify differences in plate design used in fixation of chin after Genioplasty with relation to postoperative tissue relapse.

Patients and methods: Sixteen patients suffering from a retruded chin affecting the facial esthetics which needed advancement Genioplasty were included in this study. They were selected from the outpatient clinic of the departments of oral and maxillofacial surgery and Orthodontics, faculty of Dentistry, Cairo University, with a mean age of 28 years. Facial analysis was performed through clinical intra and extra-oral photographs. Preoperative data from CT scans were documented. Digital planning was done to fabricate a cutting template and a positioning chin template. The patients were then divided into two groups; eight patients each. In Group A patients, custom digital plates designed on the computer software and processed from CAD data from titanium were used to fix the chin after Genioplasty. In group $B$ patients, conventional titanium T-shaped plate was adapted and used in fixation of the chin. Postoperative patient satisfaction and any postoperative complications were recorded. Clinical evaluation including fragment mobility and/or parasthesia was documented on one week, one month, 3 months and 6 months postoperatively. CT scan was performed immediately postoperative and on 6 months to assess fixation and/or tissue relapse through measuring the linear Antero-posterior measurements and the transverse measurements.
\end{abstract}

Results: All the patients were clinically satisfied and content about the new chin position and facial contour. All the surgeries went uneventful with no hardware exposure. Numbness of the lower lip was reported in all patients, which faded with time and reported full recovery later on. Radiographic CT scan measurements revealed the accurate postoperative measurements compared to the preoperative plan. The mean linear Pog-orbit-mental measurements showed net overall significant increase, however, with a statistical significant decrease from one period to another in each groups. In both groups, there were no statistical significant changes in mean Pog- Right mental plane and Pog- left mental plane transverse measurements. Statistical correlation between results of both groups showed no significant differences over the study period.

Conclusion: This study recommended the use of digital planning of Genioplasty and template fabrication due to the documented exact pre-to-postoperative chin alignment. The specific custom plate design and processing proved to be an insignificant hassle which can be spared by using the conventional plate for fixation after Genioplasty.

KEYWORDS: Genioplasty, digital-design, plate design.

\footnotetext{
* Lecturer of Oral and Maxillofacial Surgery, Oral and Maxillofacial Surgery Department, Faculty of Dentistry, Cairo University.

** Associate Professor of Oral and Maxillofacial Surgery, Oral and Maxillofacial Surgery Department, Faculty of Dentistry,

Cairo University.
} 


\section{INTRODUCTION}

Facial esthetics is a composite of all anatomic elements; namely hard and soft tissues and the relation to one another in a balanced proportion ${ }^{(1)}$.

The prominent position of the chin contributes to the aesthetic perception of the face through the lower third proportions and the mandibular profile and accordingly, the overall facial harmony ${ }^{(2)}$.

Different chin types vary according to ethnicity, environment and even to historical period. Along with the important role the chin offers in the overall facial appearance, society seemed to link human character to chin characteristics ${ }^{(3-4)}$.

Various surgical techniques were documented in the literature to alter the chin shape or contour. Alloplastic chin implants have been used reliably; however, osseous Genioplasty remains a fundamental technique in surgical alteration of the chin. It is the surgical reshaping of the chin for esthetic and functional purposes ${ }^{(5-6)}$.

Controversy has existed with chin surgery for many years due to the rare complications (3-5\%) that may occur after osseous Genioplasty which included wound dehiscence, lip paresthesia and tooth damage ${ }^{(7-9)}$.

Studies agreed on the minimal postoperative relapse presented after Genioplasty. The amount of relapse was previously related to the fixation rigidity as long as the magnitude of bone advancement was minimal ${ }^{(10-11)}$.

Shaughnessy et al ${ }^{(12)}$ reported the greater relapse in patients fixed with wires than those fixed with plates. However, in 2015, Moragas J and Olivier ${ }^{(13)}$ found that the difference between wire fixation and rigid fixation was statistically insignificant.

Recently, the use of computer-assisted planning software proved valuable in orthognathic surgeries. Olszewski et al ${ }^{(14)}$ presented a new procedure of computer-assisted Genioplasty through virtual planning of osteotomy lines with the production of a surgical guide used to transfer the position of the screw holes in their final position in an attempt to reduce postoperative complications.

Accordingly, in this study, computer-assisted Genioplasty was performed in both groups to compare the single variable of fixation through custom processed plate versus conventional plate.

\section{PATIENTS AND METHODS}

A total of sixteen patients were included in this study with a mean age of 28 years. They were selected from the outpatient clinics of the oral and maxillofacial surgery and the Orthodontic Departments, faculty of dentistry, Cairo University. Ethical clearance and written consents were obtained from all patients.

$\mathrm{Al}$ the patients suffered from deficient chin affecting the facial esthetics which needed advancement Genioplasty, with no required bone augmentation.

\section{Inclusion criteria:}

- Clinical features needing chin surgery only without augmentation.

- Patients above the age of 20 years.

\section{Exclusion criteria:}

- Prior surgery involving the chin.

- Medically compromised patients with impaired healing ability.

- Improper bone density.

\section{Preoperative evaluation and preparation:}

The important step of documenting the patients' chief complains and postoperative expectations was done. A series of clinical intra and extra-oral photographs were taken for all patients. Facial analysis including the face proportions and contour, midline, muscle activity and tooth to lip relation was recorded. (Fig. 1) 


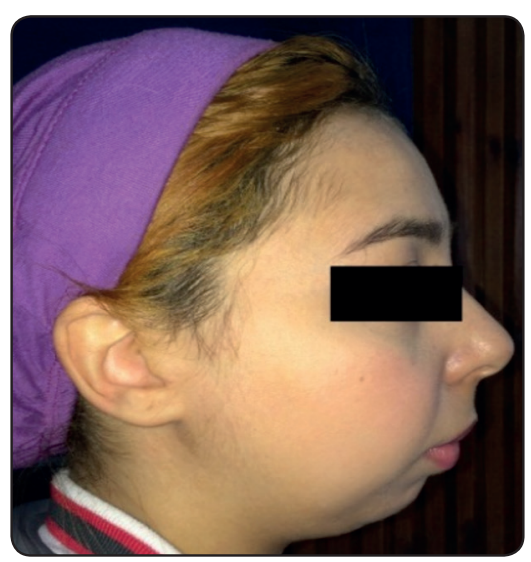

Fig. (1) Preoperative photographs showing clinical extra-oral lateral view.
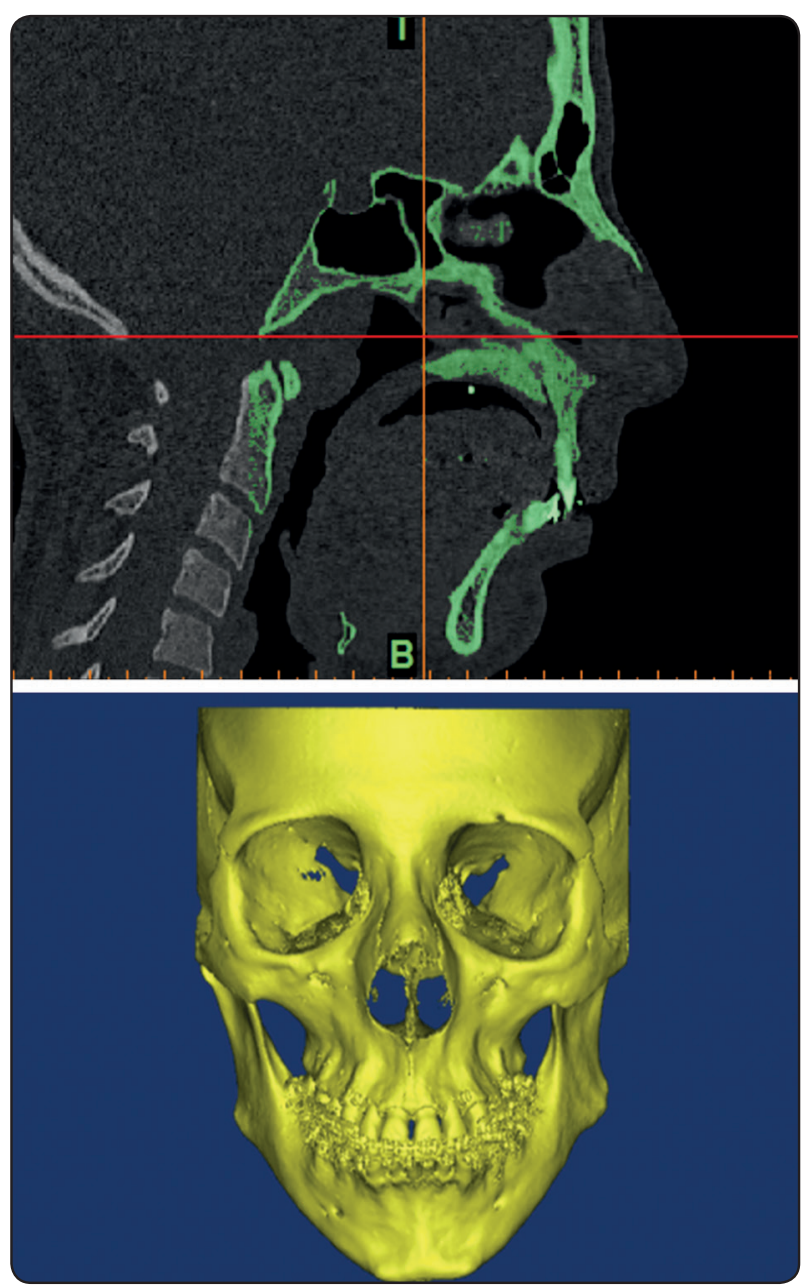

Fig. (2) Images showing the preoperative CT data.
Preoperative CT scans were taken in the supine position with the teeth biting on prepared centric relation record with relaxed lips while the Frankfurt plane is vertical to the framework.

All the patients were subjected to digital planning and a cutting template was designed according to the virtual chin osteotomy on a 3D image. A positioning template was designed to guide the chin in its new position while fixation. A virtual digital preview of the postoperative expected image was seen by each patient and consented. (Fig. 3)

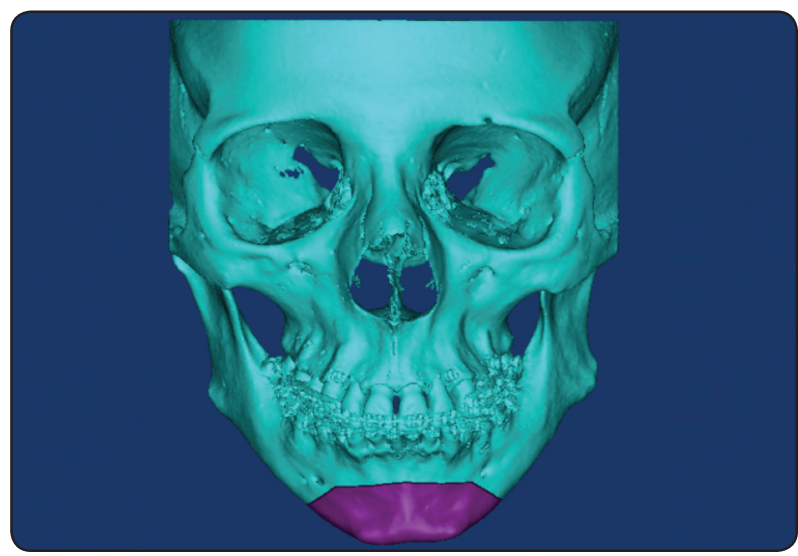

Fig. (3) A virtual image showing the planned osteotomy cut of chin Genioplasty.

\section{Patient grouping:}

The patients were then divided into two groups; eight patients each.

\section{Group A:}

Custom digital plates designed on the computer software and processed from CAD data from titanium were used for patients of this group.

The designed plate utilized two para-midline planes for fixation through two-hole boxes on the mobilized chin and the superior mandibular segment while connected across the midline with a cylindrical arm. (Fig. 4) 


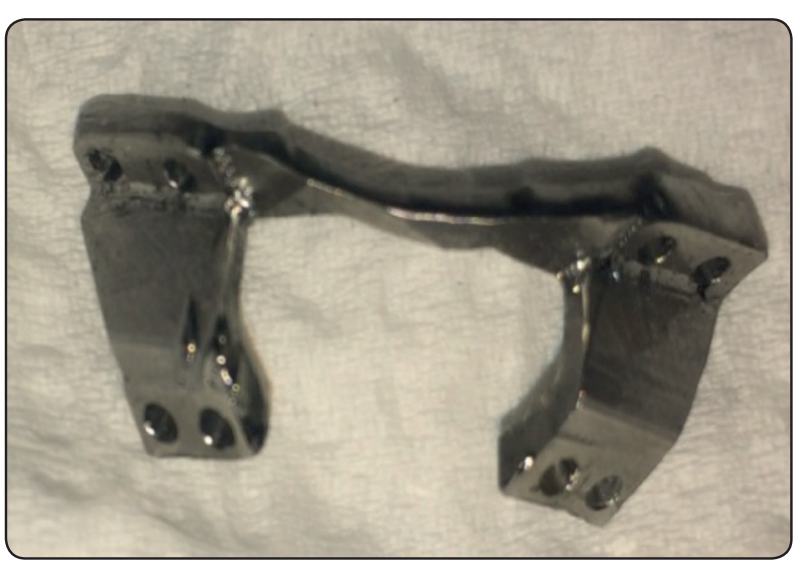

Fig. (4) A photograph showing the processed custom plate.

\section{Group B:}

A contoured and adapted conventional $2.0 \mathrm{~mm}$ titanium T-shaped midline bone plate was used in the fixation of the chin in the planned position for patients of this group.

\section{Surgical procedure:}

Mandibular intra-oral vestibular approach was utilized under general anesthesia via naso-tracheal intubation to access the required surgical region. (Fig. 5)

Careful dissection was performed avoiding the mental nerve that extends into the upper lip just below the mucosa. The visible mentalis muscle was then excised using diathermy. The inferior border of the mandible was reached via further dissection inferiorly and posteriorly at the level of the first molar teeth. (Fig. 5)

The first template, cutting template, was fixed in place and the bi-cortical osteotomy was performed using a Reciprocating saw. This template was removed and the chin was mobilized. (Fig. 6)

The second template, positioning template, was applied to guide the chin into its new position while fixation.

The chin was then fixed and secured in the new position with plates according to each group specifications using $2.0 \mathrm{~mm}$ screws with $5-10 \mathrm{~mm}$ lengths. The template was removed and soft tissue closure was performed in layers. (Fig. 7)

\section{Postoperative assessment}

The patient satisfaction with the new chin position and facial profile was recorded along the follow up period of 6 months.

Postoperative complications, as any signs of infection or dehiscence, were recorded.

The clinical evaluation of changed occlusion if present, fragment mobility and/or parasthesia was documented on one week, one month, 3 months and 6 months postoperatively.

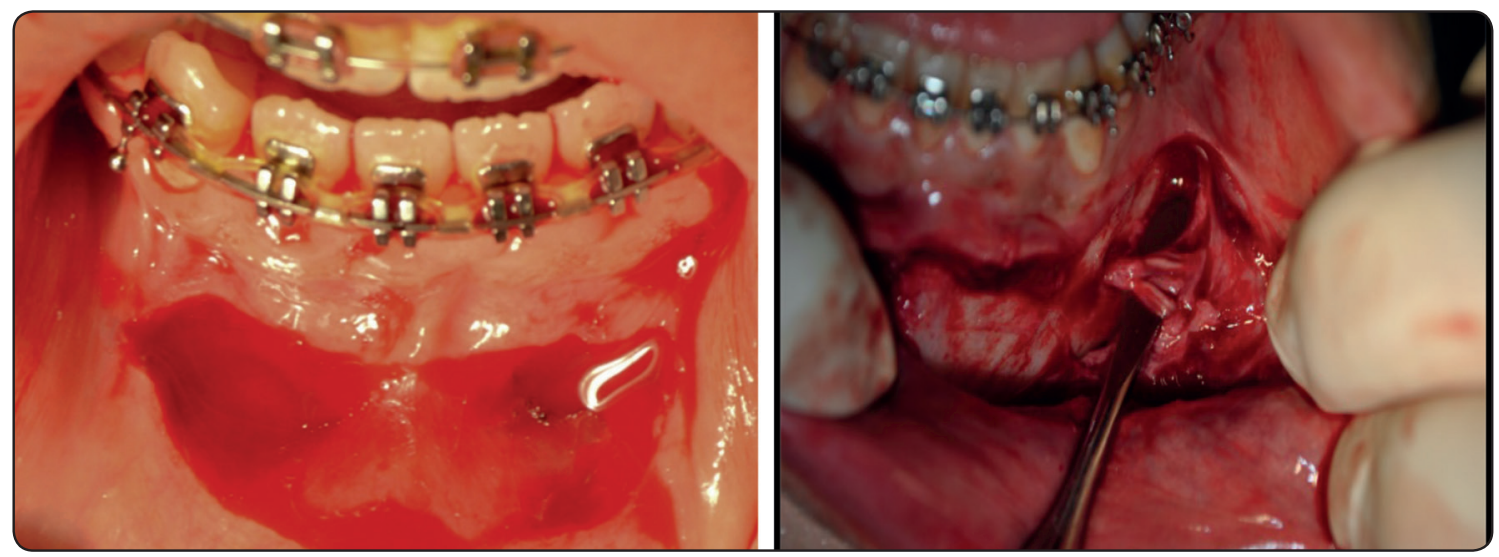

Fig. (5) Photographs showing the intra-oral approach and mental nerve dissection. 
CT scan was performed immediately postoperative and on 6 months to assess fixation and/or tissue relapse over the follow up period through measuring:

- The linear Antero-posterior measurements; the distance from Pog to Orbito-mental plane which is the plane from mental foramen in one side, the infra-orbital foramen of the same side to the infra-orbital foramen of the other side and again the mental foramen of the original side.

- $\quad$ The transverse measurements; from Pog to the right and left mental planes (parallel to the mid sagittal plane)

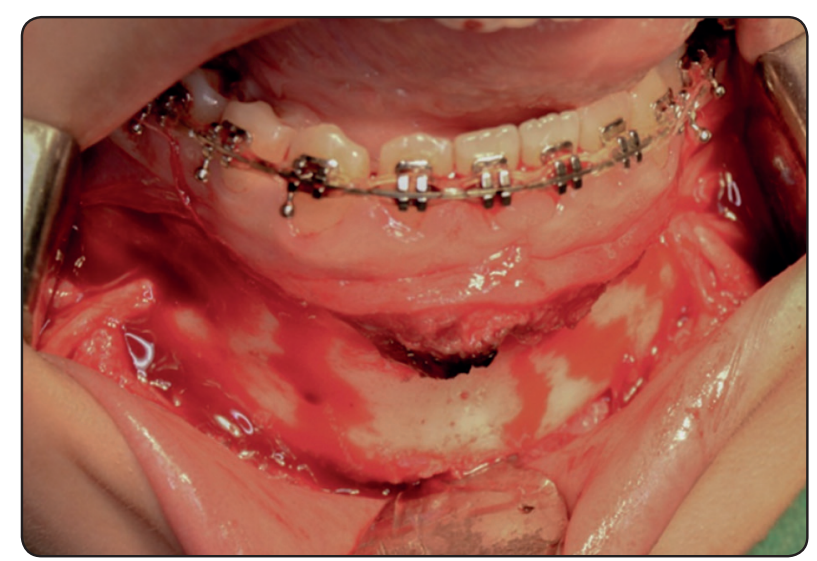

Fig. (6) A photograph showing the osteotomy cut with the reciprocating saw.

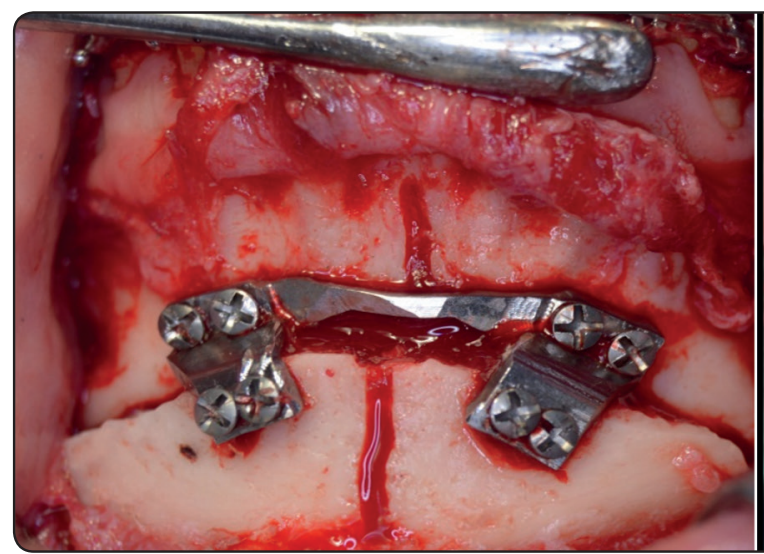

\section{RESULTS}

A total of sixteen patients with deficient retruded chin needing advancement chin Genioplasty were included in this study with a mean age of 28 years. They were 11 females and 5 males.

All the surgeries went uneventful with a normal tolerable postoperative pain and swelling.

No wound dehiscence or hardware exposure was reported in this study. All the patients were clinically satisfied and content about the new chin position and facial contour. (Fig. 8)

All patients reported numbness of the lower lip indicating mental nerve affection during the first week postoperatively, which faded with time and reported full recovery in all patients in the subsequent follow-up visit.

Radiographic CT scan measurements revealed the accurate postoperative measurements compared to the preoperative plan.

Along the follow up, in the mean Pog-orbitmental measurements, despite of the net overall significant increase, the linear antero-posterior measurements detected a statistical significant decrease from one period to another in each group. (Fig. 9)

While in the transverse measurements of each group, through all the study intervals, there were no statistical significant changes in mean PogRight mental plane and Pog- left mental plane measurements. (Fig. 9)

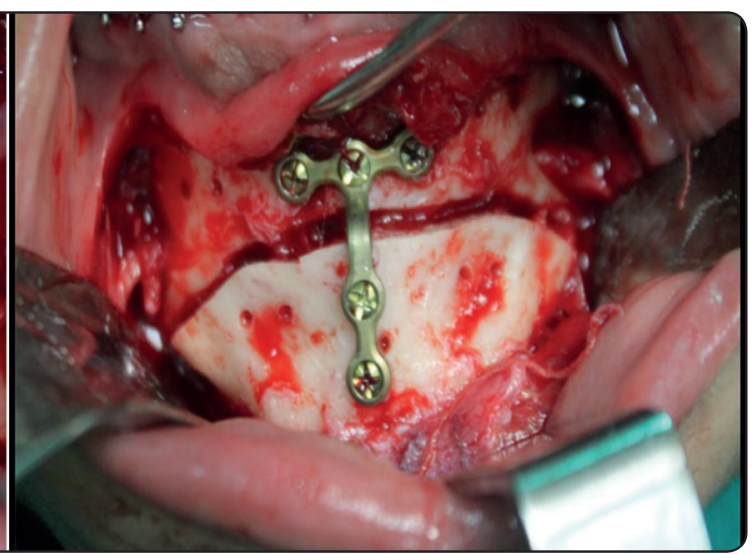

Fig. (7) Photographs showing the fixed custom plate and fixed the conventional plate respectively. 
Statistical correlation between results of both groups showed no significant differences over the study period.

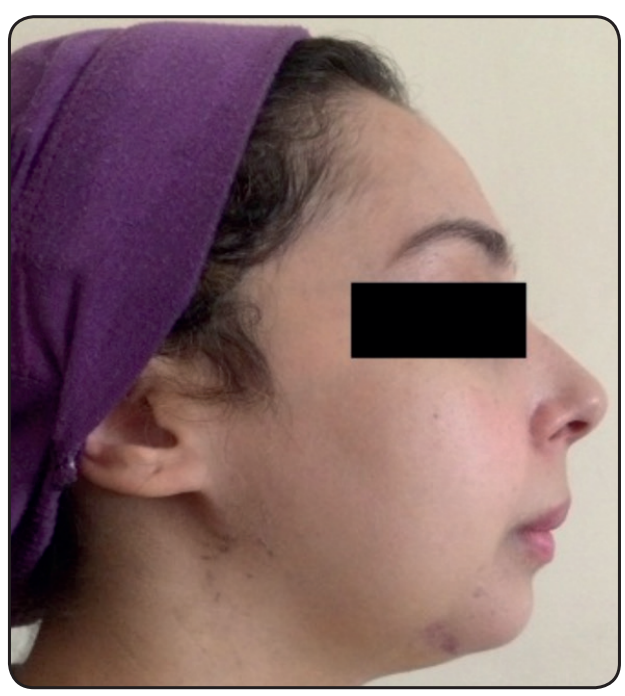

Fig. (8) A photograph showing the postoperative clinical facial profile.

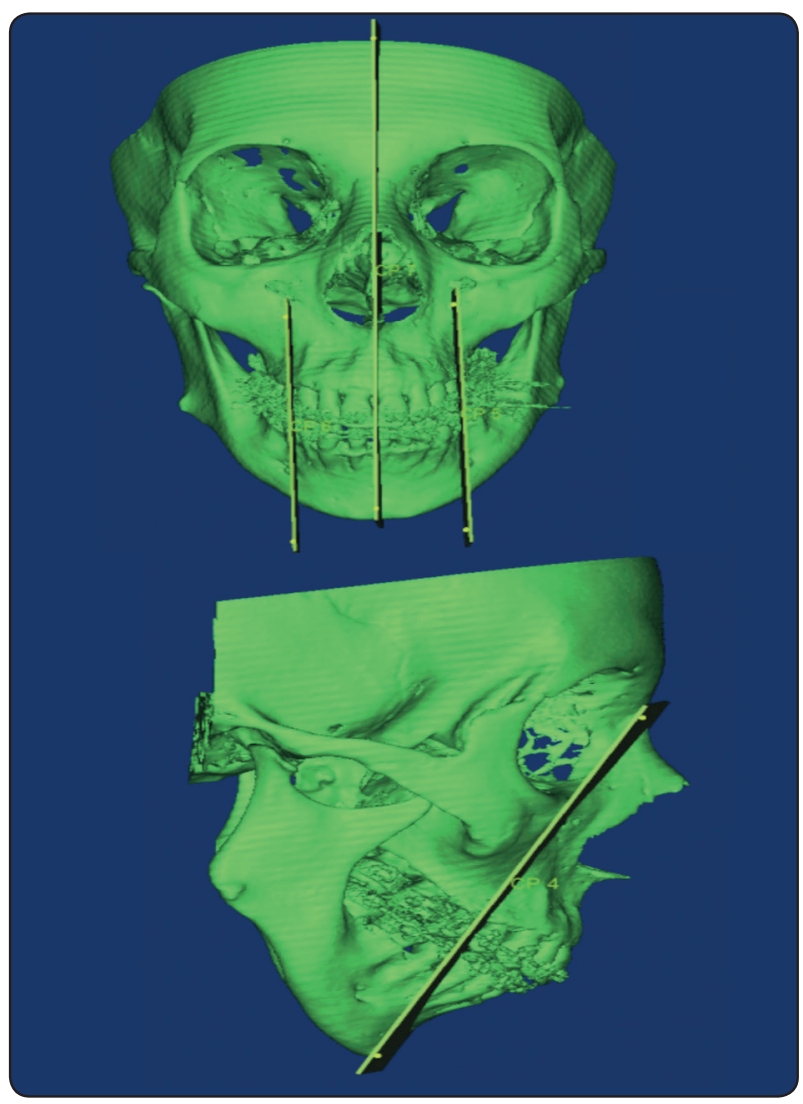

Fig. (9) An image showing the Pog-orbito-mental plane measurements and the transverse Pog-Mental plane measurements respectively.

\section{DISCUSSION}

Several techniques were utilized to deal with the morphologic deformities of the chin aiming to alter the chin contour in a reliable manner ${ }^{(12)}$.

Osseous Genioplasty remains the most reliable procedure in surgical alteration of the chin with a comparatively stable results and low risk of complications ${ }^{(10,15)}$.

In the patients of this study, a female predominance of $69 \%$ was recorded. This came in accordance with Breece and Nieberg ${ }^{(16)}$ who attributed this to the greater interest and higher motivation for facial cosmetics and looks in women

Similar to other studies ${ }^{(12,17)}$, the recorded mean age of our patients was about 28 years. This was due to the fact that facial appearances usually play a more significant role in the life of this age group.

An immediate postoperative normal tolerable postoperative pain and swelling were detected, and faded before the next visit. This was considered a normal reaction to the surgery itself; open wound and bone osteotomy.

After the surgery, there was no reported hardware exposure or wound dehiscence in this study. This was due to the thick covering mucosa and muscle with the smooth thin utilized plates ${ }^{(18)}$.

The reported numbness of the lower lip in all patients was considered a normal postoperative reaction due to tissue handling and pressing edema on the mental nerve. They all recovered full sensation with time. This was expected due to the meticulous clear identification of the mental nerves and avoidance of undue traction during surgery. This was supported by many authors ${ }^{(18-19)}$ who claimed that neuropraxia of the mental nerve during retraction is unavoidable and hence the common postoperative transient paresthesia of the lower lip in Genioplasty patients. 
All the patients showed postoperative satisfaction regarding the new chin position and facial contour. This was because of the preoperative preview of the virtual picture seen and approved by the patient after digital chin advancement according to radiographic analysis and planned surgery. For this, the used mimics program in both groups was proved useful, besides its advantages of saving time and giving more accurate results ${ }^{(20-21)}$.

In both groups, Computer-assisted Genioplasty was performed with cutting and positioning preformed templates. This was transferred in the resulted outcome in the form of the accurate postoperative measurements compared to the preoperative plan. This followed recommendations of previous studies, which declared 3D software incorporation to be the next step in the evolution of computer-assisted orthognathic surgery to achieve more accurate results, shorter processing time and better esthetics ${ }^{(22)}$.

It opposed to Kaipature et al ${ }^{(23)}$ who claimed that the clinical processing of the collected 3D information might increase the magnitude of errors.

Negligible changes were detected in the transverse bony measurements, Pog-(right and left) mental planes. This was due to the lack of surgical transverse chin movements performed in patients of this study.

An overall net significant increase in the Pog-orbit-mental measurements was recorded. It was attributed to the net change between the preoperative and the postoperative analysis due to the corrected chin deformity in each case. Keeling et al ${ }^{(24)}$, Mobarak et al ${ }^{(25)}$ and Thuer et al ${ }^{(26)}$ stated similar outcomes when they compared preoperative and postoperative chin positions.

During the follow up intervals, a continuous small decrease in the Pog-orbit-mental measurements was shown in both groups. This indicated minor relapse and/or resorption after Genioplasty regardless of the used plate in fixation. It was explained by Talebzadeh and Porgel (10) who confirmed the presence of relapse in a small percent after Genioplasty.

The fact that it was detected in both groups with the same surgical technique and regardless of the way of fixation, along with the statistical insignificant difference between both groups, proves the insignificant effect of the plate design on relapse incidence. This came in opposition with other studies which claimed that the long term stability of rigid internal fixation is better than non-rigid fixation.

However, our results were further approved by several authors ${ }^{(27)}$ who declared other factors that may influence relapse; as the effect of soft tissue thickness, muscle tone and activity and postoperative osseous remodeling.

\section{CONCLUSION AND SIGNIFICANCE}

The documented exact pre-to-postoperative alignment advocates the use of digital panning of Genioplasty and template fabrication. However, the specific plate design and processing proved to be a hassle which can be spared by using the conventional plate for fixation after Genioplasty.

Different plate designs and muscle tone measurements are evidently needed in further studies to verify the exact causes of relapse after Genioplasty.

\section{REFERENCES}

1. Sykes J: Aesthetic correction of chin deformities-Bony Genioplasty. J Aesthetic Plastic Surg; 6: 4306, 2002.

2. Farkas LG, Katic MJ, Hreczko TA, Deutsch C, Munro IR. Anthropometric proportions in the upper lip-lower lip-chin area of the lower face in young white adults. Am J Orthod; 86: 52-60, 1984.

3. Jones BM., Vesely MJ.: Osseous Genioplasty in facial aesthetic surgery-a personal perspective reviewing 54 patients. J Plast Reconstr Aesthetic Surg; 59:1177, 2006.

4. Danahey DG., Dayan SH., Benson AG., et al: Importance of chin evaluation and treatment to optimizing neck rejuvenation surgery. Facial Plast Surg; 17:91, 2001.

5. Chang EW., Lam SM., Karen M., et al: Sliding Genioplasty for correction of chin abnormalities. Arch Facial Plast Surg; 3:8, 2001. 
6. Wolfe SA., Rivas-Torres MT., Marshall D.: The Genioplasty and beyond: An end-game strategy for the multiply operated chin. Plast Reconstr Surg; 117:1435, 2006.

7. Frodel JL., Sykes JM., Jones JL.: Evaluation and treatment of vertical microgenia. Arch Facial Plast Surg; 6:111, 2004.

8. Celik M., Tuncer S., Buyukcayir I.: Splitting advancement genioplasty: A new Genioplasty technique. Ann Plast Surg; 43:148, 1999.

9. Richard O., Ferrara JJ., Cheynet F., et al: Complications of Genioplasty. Rev Stomatol Chir Maxillofac; 102:34, 2001.

10. Talebzadeh N, Pogrel MA: Long-term hard and soft tissue relapse rate after genioplasty. Oral Surg Oral Med Oral Pathol Oral Radiol Endod 91:153, 2001.

11. Miles A., Leach L.: Osseous Genioplasty: Technical considerations. Operative techniques in otolaryngology; 18: $181,2007$.

12. Shaughnessy S., Mobarak KA., Hogevold HE., et al: Longterm skeletal and soft-tissue responses after advancement Genioplasty. Am J Orthod Dentofacial Orthop; 130: 8, 2006.

13. Moragas $\mathbf{J}$ and Olivier et al. A systematic review on softto-hard tissue ratios in orthognathic surgery part II: Chin procedures. Journal of Cranio-Maxillo-Facial Surgery; 7: 1,2015 .

14. Olszewski R., Zech F., Consnard G. et al.: Three-dimensional computed tomography cephalometric craniofacial analysis: experimental validation in vitro. Int. J. Oral Maxillofacial surg; 36:828, 2010.

15. Kim GJ., Jung YS., Park HS ., Lee EW.: Long-term results of vertical height augmentation Genioplasty using autogenous iliac bone graft. Oral Surg Oral Med Oral Pathol Oral Radiol Endod; 100: 51, 2005.

16. Breece GL., Nieberg LG.: Motivations for adult orthodontic treatment. J Clin Orthod; 20: 166, 1986.

17. Erbe C., Mulie' R. M., Ruf S.: Advancement Genioplasty in Class I patients: predictability and stability of facial profile changes. Int. J. Oral Maxillofac. Surg; 40: 1258, 2011.
18. Phillips C., Essick G., Zuniga J., et al: Qualitative descriptors used by patients following orthognathic surgery to portray altered sensation. J Oral Maxillofac Surg; 64:1751, 2006.

19. Pektas ZO., Kircelli BH., Cilasun U., et al: The accuracy of computer-assisted surgical planning in soft tissue prediction following orthognathic surgery. Int J Med Robot; 3:64, 2007.

20. Xia J, Gateno J., Teichgraeber J: Computer-Aided Surgical Simulation for Orthognathic Surgery. J Oral Maxillofac Surg; 35:106, 2008

21. Talwar RM., Chemaly D.: Information and computer technology in oral and maxillofacial surgery. Oral Maxillofac Surg Clin North Am; 20:79, 2008.

22. Mäkitie A, Paloheimo KS, Björkstrand R, Salmi M, Kontio $\mathrm{R}$, Salo J, et al. Medical applications of rapid prototyping-three-dimensional bodies for planning and implementation of treatment and for tissue replacement. Duodecim; 126:143, 2010.

23. Kaipatur N., Al-Thomali Y., Flores-Mir C.: Accuracy of Computer Programs in Predicting Orthognathic Surgery Hard Tissue Response J Oral Maxillofac Surg; 67:1628, 2009.

24. Keeling SD., Dolce C., Van Sickels JE., Bays RA., Clark GM., Rugh JD.: A comparative study of skeletal and dental stability between rigid and wire fixation for mandibular advancement. Am J Orthod Dentofacial Orthop; 117: 638, 2000.

25. Mobarak KA., Espeland L., Krogstad O., Lyberg T.: Mandibular advancement surgery in high-angle and low-angle Class II patients: Different long-term skeletal responses. Am J Orthod Dentofacial Orthop; 119: 368, 2001.

26. Thüer U., Ingervall B., Vuillemin T.: Stability and effect on the soft tissue profile of mandibular advancement with sagittal split osteotomy and rigid internal fixation. Int J Adult Orthod Orthognath Surg; 9: 175, 1994.

27. Shaik M., and Koteswar N. Comparison of rigid and semi rigid fixation for advancement Genioplasty. J Maxillofac Oral Surg; 12: 260-265, 2013. 